\title{
Hazard Identification using Risk Assesment for A Tyre Manufacturing Process
}

\author{
Raj Pradeesh T, Venkumar P, Saravanamani M
}

\begin{abstract}
Today's industries play a major role to develop and create new innovation products in manufacturing domain. The aim of this project is to identify the hazards, assess the risk and its root cause and to develop a control measures so that the major and minor hazards can be controlled in the tyre manufacturing industry and the workers will be working in a hazard free and safety environment. Material handling is the biggest cause of reportable accident in rubber industry and also hit by moving objects, falling objects, Noise, Fire etc... This can be identified and controlled by using the technique called HIRARC .By using these techniques the risks can be identified and the best safety measures can be implemented in the industry
\end{abstract}

Keywords- HIRARC, Hazards, Risk Assessment, Tyre Industry

\section{INTRODUCTION}

Tyre manufacturing industry comprising of operations like Raw material handling, weighing, Mixing, Milling, Extruding, calendaring, assembly, curing, finishing and inspection. Due to the various processes in tyre manufacturing industry the hazards are very high. Employees working in industrial processing and working with rubber products leads to hazards like physical, chemical, biological etc... The data's has been collected at Tyre Manufacturing located in Madurai, by interacting with around 20 peoples who are all working in different units in the tyre manufacturing plants. TVS SRICHAKRA is a member of TVS groups, the largest auto ancillary group in India. It is the No.1 in Motorcycle tyres, is a leading manufacturer of tyres and tubes for two and three Wheelers in India. The Main objective of this work focus towards: To identify types of Hazard in work area, To make Risk Assessment, To suggest Risk Control to Organization, To implementing Risk Controls, To review Risk Controls.
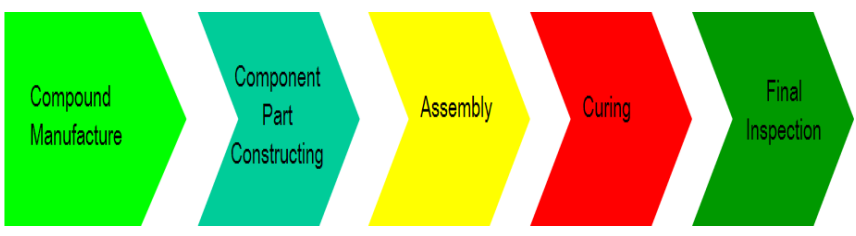

Figure 1: Process of Operation

Revised Manuscript Received on December 30, 2019.

* Correspondence Author

Raj Pradeesh $\mathbf{T}^{*}$, Department of Mechanical Engineering Kalasalingam Academy of Research and Education, Krishnankoil, India. Email: rajpradeesh29@gmail.com

Venkumar P, Department of Mechanical Engineering Kalasalingam Academy of Research and Education, Krishnankoil, India. Email: p.venkumar@klu.ac.in

Saravanamani M, Department of Mechanical Engineering Kalasalingam Academy of Research and Education, Krishnankoil, India. Email: saravanamani36@gmail.com

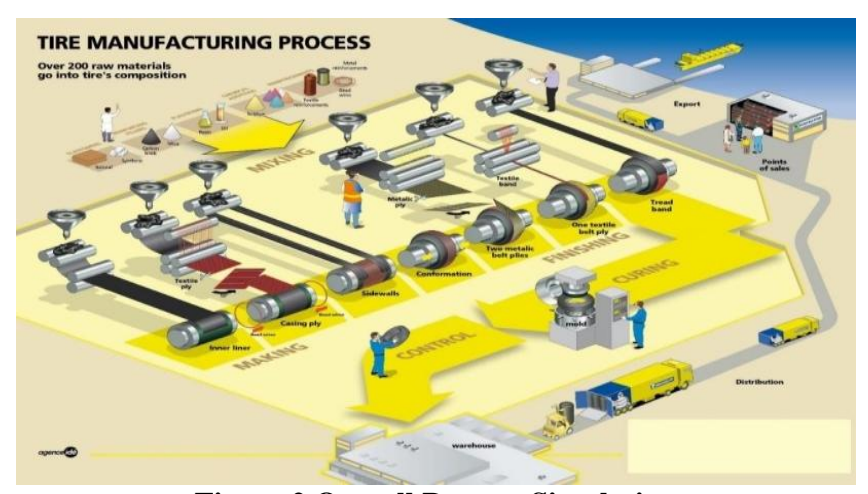

Figure 2 Overall Process Simulation

The common processes of Tyre manufacturing are: Mixing, Milling, Extruding, Calendaring, Bead making. Building (Fabrication), Vulcanizing, Finishing.

\section{LITERATURE REVIEW}

Weijun Li et al. [1] proposed the proactive risk assessment control process for an industrial process by applying the JHA technique (Job Hazard Analysis) Techniques and Resilience Engineering Techniques. The outcome of the risk identification are minimize the risk and hazards present in the workplace that can lead to improve the safety culture in Industrial sectors

Sancheza et al [2] approach the risk reduction techniques to maintain a health and safety environment in the workplace. In this paper the author focusing the hand arm vibration as the critical factors in the workplace. Finally the author concluded the outcome of hazards identification is very minimal and the corresponding risk can be reduced. The author proposed the method used as the model for development of industrial environments to maintain a safety culture.

Rita Lamboglia et al [3] this investigation represents the causes of hazards and risk parameters that are related with the organizational factors. Behind that study it represents following relations to the organizational factors for risk management process and check the implementation level for the presence of surrounding factors related and added in the webpages of organization. The systematic approach conclude that mitigation of hazards and risk level in the workplace. Syaza I. Ahmad et al [4] develop the hazard assessment methodology for erection of chemical plants. The methodology shows the development of process hazard analysis techniques in early stage in terms of design concepts. The outcome of the analysis techniques are similarity difference studies between early stage case study incident analysis. Mira Hidajat et al [5] develop the matrix for the material analysis in rubber manufacturing industries. The results shows the matrix correlation of the various rubber manufacturing chemical particles that are present in the industries. 
Pascal Petit et al [6] conducted the investigation about the exposure of hydrocarbons of various industries and causes of lung cancers for the industrial workers. The study concludes and give the following outcomes are risk estimation of lung cancer diseases, Decrease the hazards and maintain the health environment.

Ruru Han et al [7] conducted the case study on atmosphere disasters happened in china. The case study concluded that manmade habitats and climatic change are the causes of Natural disasters. This method is one of the model to predict the factors caused by the monsoon disaster parameters.

Yongbo Li et al [8] conducting risk assessment in thermal power plants by applying the ISM methodology (Interpretive Structural modelling). The outcome of the risk assessment insulation failure is the potential factors that may cause accidents inside the power plants and can be precautions can be implemented based on the available potential failures levels.

Shahidul Islam et al [9] identify the fire hazards encountered in garment industries. The assessment was primarily conducted out built on Initial workers Questinarraie surveys. Next part information carried out with all necessary sources by relating with the previous data's collected. The analysis conclude that this industry is very poor compared with the other garment industry located in by near the filed in mitigating and identification of fire accidents.

\section{METHODOLOGY}

The Hazards has to be identified based on the process in each plant and then its severity has to be noted, risk has to be assessed and it has to be noted for tabular representation. Then the control and effective measures have to be identified and taken for further proceeding. The HIRARC table has to be made for Mixing and Extruder so that the problem can be easily identified, its control measures are noted and then optimization tool AHP is carried out for the same process for further clarity regarding the Hazards. The purpose of this guideline is to provide a systematic and objective approach to assessing hazards, its associated risks that will provide an objective measure of an identified hazard as well as provide a risk controlling method. Occupational Safety and Health Act 1994 (Act 514) for the employer to provide a safe workplace to their employees and other related person is prescribed as the general duty

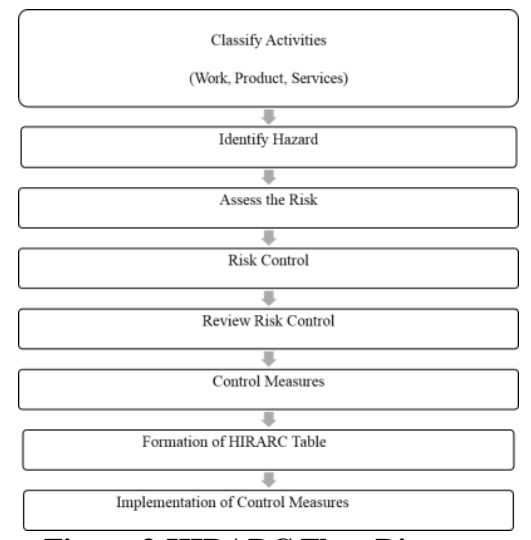

Figure 3:HIRARC Flow Diagram

\section{A. About Risk}

Risk is the combination of the occurrences of accidents in possible ways and impact of incident may be major or minor of a quantified dangerous occurrence encountered. In general, risk can be calculated by the following equation.

\section{Risk $=$ Likelihood $\mathrm{x}$ Severity}

The reasons of conducting HIRARC for the following methodologies behind on every industry: - To categorize all the influences that may origin injury to workers and others assets to machineries (hazards, risks), To permit occupiers to strategy, familiarize and point out protective points to ensure that the risks are adequately controlled at all times. The purpose of hazard identification is to highlight the critical operations of tasks, that is, those tasks posing significant risks to the health and safety of employees working conditions or activities performed.

\section{B. Risk Estimation}

Risk estimation is the resolve the probability of accident occurrences and sources, impact of the reliable coincidence/event orders, to identify the direction of sources of the events and to importance known risks. It can be done by qualitative, quantitative or semi quantitative method.

\section{TABLE I RISK EVALUATION MATRIX TABLE}

\begin{tabular}{|c|c|c|c|c|c|}
\hline $\begin{array}{c}\text { LIKELIHO } \\
\text { OD } \\
\text { OF } \\
\text { HAZARDS }\end{array}$ & $\begin{array}{c}\text { INSIG } \\
\text { NIFICA } \\
\text { NT(1) }\end{array}$ & $\begin{array}{c}\text { MINO } \\
\text { R (2) }\end{array}$ & $\begin{array}{c}\text { MODERA } \\
\text { TE } \\
(3)\end{array}$ & $\begin{array}{c}\text { MAJO } \\
\text { R (4) }\end{array}$ & $\begin{array}{c}\text { FATAL } \\
(5)\end{array}$ \\
\hline RARE (1) & 1 & 2 & 3 & 4 & 5 \\
\hline $\begin{array}{c}\text { UNLIKELY } \\
(2)\end{array}$ & 2 & 4 & 6 & 8 & 10 \\
\hline $\begin{array}{c}\text { POSSIBLE } \\
(3)\end{array}$ & 3 & 6 & 9 & 12 & 15 \\
\hline LIKELY (4) & 4 & 8 & 12 & 16 & 20 \\
\hline $\begin{array}{c}\text { ALMOST } \\
\text { CERTAIN } \\
\text { (5) }\end{array}$ & 5 & 10 & 15 & 20 & 25 \\
\hline
\end{tabular}

The purpose of hazard identification and risk assessment is to highlight the critical operations of tasks that poses significant risks to the health and safety of employees as well as highlighting those hazards pertaining to certain equipment due to energy sources, working conditions or activities performed. Identifying required corrective action to minimize the risk or eliminate the hazard.

\section{TABLE: II Risk Level Table}

\begin{tabular}{|c|c|}
\hline \multicolumn{2}{|c|}{ RISK LEVEL } \\
\hline 1 to 2 & LOW \\
\hline 3 to 6 & MEDIUM \\
\hline 7 to 12 & HIGH \\
\hline $\begin{array}{c}\text { More than } \\
12\end{array}$ & EXTREME \\
\hline
\end{tabular}




\section{RISK ASSESMENTS FOR MIXING PLANT AND EXTRUDER OPERATIONS}

The Problems identified in the tyre manufacturing industry based on the previous incident analysis, lesson learning techniques, Accident reporting techniques and Job Safety analysis. Study all the overview process and identify the serious potential hazards present in workplace. This study focus the high hazards present in the new mixing plants and extruder plants. Although with the reference of risk assessment procedures methodology, initially select the process of the tyre manufacting and activities performed by the workers. Next categorize and identify the hazards based on the activities. Conduct the Risk assessment for marking the probability of occurrence a, severity ranges and risk ratings.

The sample activities shows the amount of hazards present in the workplace. The corresponding probability of occurrences, severity ranges and risk rating is shown in Table III for reference. The Risk rating is calculated based on the risk evualtion matrix shown in Table II for reference.

\section{TABLE III HIRA TABLE FOR TWO OPERATIONS}

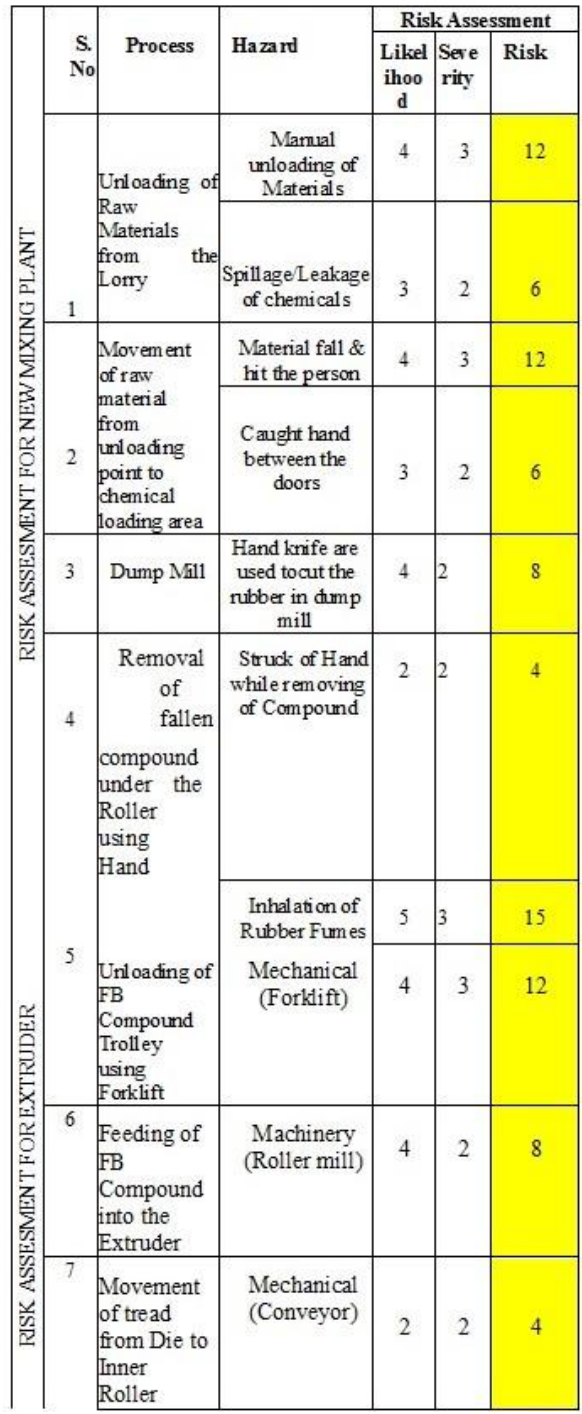

\section{RESULT AND DISCUSSION}

Direct Loading Mill has the highest risk factor in mixing process. Over $35 \%$ of risk is due to direct falling of mixed rubber into the dump mill. Safety mask can be provided so that the chances of inhaling a carbon present the heated rubber will be minimum

TABLE IV: Comparison Risk Scores for Each Activities

\begin{tabular}{|c|c|c|}
\hline $\mathrm{SNO}$ & PROCESS & $\begin{array}{l}\text { RISK } \\
\text { SCORES }\end{array}$ \\
\hline 1. & $\begin{array}{l}\text { Unloading of Raw Materials from } \\
\text { the Lorry }\end{array}$ & 9 \\
\hline 2. & $\begin{array}{l}\text { Movement of raw material from } \\
\text { unloading point to chemical } \\
\text { loading area }\end{array}$ & 8 \\
\hline 3. & $\begin{array}{l}\text { Weighing } \quad \& \quad \text { Mixing } \quad \text { of } \\
\text { Chemicals }\end{array}$ & 9 \\
\hline 4. & $\begin{array}{l}\text { Loading of Raw Rubber \& mixed } \\
\text { chemicals into the Banbury using } \\
\text { Conveyors }\end{array}$ & 8 \\
\hline 5. & Dump Mill & 15 \\
\hline 6. & $\begin{array}{l}\text { Removal of fallen } \\
\text { compound under the Roller using } \\
\text { Hand }\end{array}$ & 15 \\
\hline 7. & Warming Mill & 6 \\
\hline 8. & $\begin{array}{l}\text { Dipping of compound in Soap Oil } \\
\text { solution }\end{array}$ & 8 \\
\hline 9. & Wig wag & 4 \\
\hline 10 . & $\begin{array}{l}\text { Movement of MB Compound } \\
\text { trolley from Wig wag to FB } \\
\text { Banbury }\end{array}$ & 10 \\
\hline 11. & $\begin{array}{l}\text { Loading of FB Compound trolley } \\
\text { to the tractor }\end{array}$ & 8 \\
\hline 12. & $\begin{array}{l}\text { Movement of Tractor to Extruder, } \\
\text { Bead Winding, Calendaring }\end{array}$ & 6 \\
\hline
\end{tabular}

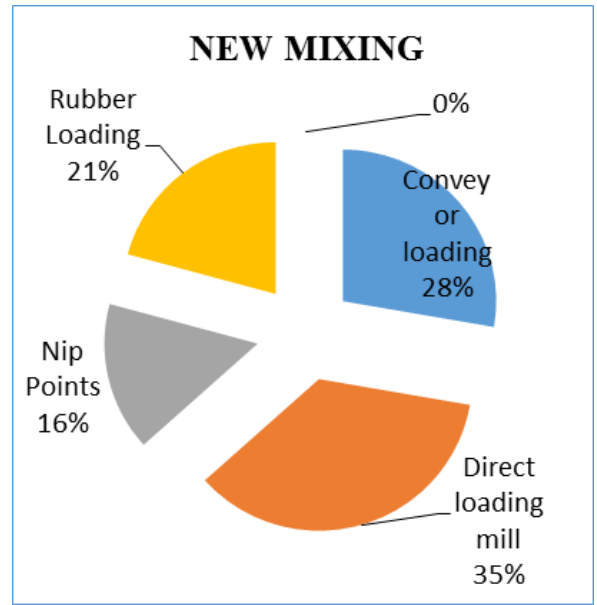

Figure 4 Risk Analysis for New Mixing Operation

Improper faulty is the highest risk factor in extruder process. Over $46 \%$ of risk is due to the loading of FB rubber into the extruder. When the rubber get stuck in the die inside the extruder, during cutting of excess rubber there is a chances of hand getting stuck un the hopper and chances of hand gets broken. 


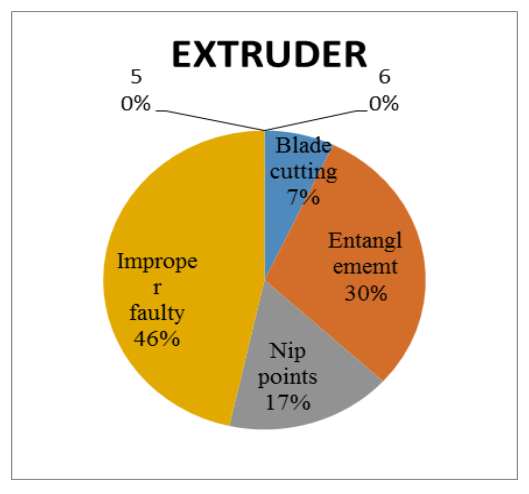

Figure 5 Risk Analysis for Extruder operation

\section{CONCLUSION}

Around $40 \%$ of report in Health Safety \& Environment is based on rubber industries material handling causage.In Tyre Industries accidents are undertaken via falling/moving of objects, Slips and Trips, Rubber dust,Fire,etc..It can be overcome by using a technique named HIRARC. This technique is used to identify the Hazard, Types of Hazards to be implementing, and Risk Assessment to be made with the support of Risk Controls Units.

\section{REFERENCES}

1. W Li, Y Sun, Q Cao, M He, and Y Cui, "A proactive process risk assessment approach based on job hazard analysis and resilient engineering". Journal of Loss Prevention in the Process Industries, Vol. 59, 2019, 54-62.

2. A Sánchez,., C González,.., and F Brocal. "Assessment of emerging risk level by occupational exposure to hand-arm vibrations: Approach under uncertainty conditions". Safety Science, Vol.114,2019, 140147.

3. R Lamboglia, F Paolone, \& D Mancini, "Determinants of the implementation of environmental risk indicators: Empirical evidence from the Italian manufacturing context. Corporate Social Responsibility and Environmental Management", Vol.26(2),2019, 307-316..

4. S.I Ahmad, H.Hashim, M. H Hassim, and R Rashid. "Development of hazard prevention strategies for inherent safety assessment during early stage of process design". Process Safety and Environmental Protection, Vol.121,2019, 271-280.

5. M Hidajat, D.M McElvenny, W.Mueller, , P Ritchie, J. W.Cherrie, A Darnton, and F De Vocht,"Job-exposure matrix for historical exposures to rubber dust, rubber fumes and n-Nitrosamines in the British rubber industry”. Occup Environ Med, Vol.76(4),2019, 259267.

6. P.Petit,A.Maître,R Persoons, and D. J Bicout,"Lung cancer risk assessment for workers exposed to polycyclic aromatic hydrocarbons in various industries". Environment international, Vol.124, 2019,109120.

7. R Han, B Zhou, L An, H Jin, L Ma, N Li, M Xu, L.Li,. "Quantitative assessment of enterprise environmental risk mitigation in the context of Na-tech disasters". Environmental monitoring and assessment,Vol. 191(4), 2019,210.

8. Y.Li, B.Sankaranarayanan., D. T Kumar, A Diabat,. "Risks assessment in thermal power plants using ISM methodology". Annals of Operations Research, 2019,1-25.

9. S.Islam, \& R. I. Roman. "Assessment of Fire Hazard on the Readymade Garment Industry in Chittagong City, Bangladesh". Indonesian Journal of Environmental Management and Sustainability, Vol. 3(1),2019, 20-28.

\section{AUTHORS PROFILE}

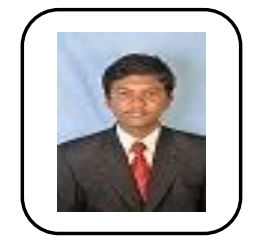

Rajpradeesh T Working as Assistant Professor at Kalasalingam Academy of Research \& Education. His research interest in the domain of Industrial Safety Engineering. He published one SCI Paper in the API Publication.

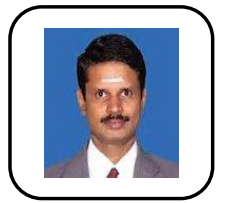

Venkumar $\mathbf{P}$ Working as Senior Professor a Kalasalingam Academy of Research and Education. He contributed more than 10 years in Industrial Engineering domain and published around 39 Research papers.

Saravanamani M Pursue his PG Degree in Industrial Safety Engineering at Kalasalingam Academy of Research and Education-Krishnankoil. 